Neuroepidemiology 2009;32:312

DOI: $\underline{10.1159 / 000208796}$

\section{Racial/Ethnic Differences in Stroke in Young Adults}

Norrina Allen

Department of Chronic Disease Epidemiology, Yale School of Public Health Center for Outcomes Research, New Haven, Conn., USA

Racial and ethnic differences in the risk of stroke are widely recognized, and these differences are even greater among younger populations. Younger adults have a lower risk of stroke; however, they represent a major public health priority as they live longer with their disabilities, have complications throughout their life, and have a longer period of time of lost productivity [1]. The report by Pathak and Sloan [2] in this issue of Neuroepidemiology presents evidence that blacks are over 3 times more likely than whites to be hospitalized for a stroke, and that Hispanics also have a higher stroke hospitalization rate as compared to whites. In addition, they found that after risk adjustment, the fatality rates for stroke are similar for blacks and whites. Interestingly, even after adjustment, Hispanic patients had a 34\% decreased likelihood of dying in hospital. These findings support the idea that the excess stroke mortality in blacks $[3,4]$ is due to a higher incidence rate, not a higher fatality rate; therefore, it is important that research continue to explore the racial/ethnic differences in risk factors and access to care.

Prior research has shown race/ethnic differences in stroke incidence in young adults among specific urban communities. Among 74 young adults, aged 20-44 years, in the Northern Manhattan Stroke Study (NOMASS) [5], blacks had 2.4 times the risk of stroke as compared to whites. Although not statistically significant, the NOMASS findings suggest that blacks are at greater risk of stroke than whites. These findings were corroborated by similar findings in the Greater Cincinnati/Northern Kentucky region [6], in which blacks of all younger age groups $(<35,35-44$, and $45-54$ years) were significantly more likely to have a stroke as compared to whites [RR 2.2 (1.3-3.1), 5.0 (3.9-6.1), and 2.6 (2.0-3.2), respectively]. As part of the Baltimore-Washington Cooperative Young Stroke Study, the odds of ischemic stroke in blacks versus whites were 2.1 (95\% CI, 1.2-3.6), and the odds of intracerebral hemorrhage for blacks to whites were 3.1 (95\% CI, 1.3-7.4) [7].

The findings of higher stroke incidence for blacks extends beyond the United States, and is consistent with a higher incidence among other black populations. In the United Kingdom, the South London Stroke Registry found an annual incidence rate for cerebral infarction of 1.86 per 1,000 for blacks and 0.79 per 1,000 for whites among individuals age 35-64 years [8]. These higher incidence rates are similar to those of other black populations around the world including those in South Africa [9], Libya [10], and Martinique [11].
While the magnitude of the findings in this issue are similar to those of other studies, the study of Pathak and Sloan [2] is one of the largest to examine racial/ethnic differences in stroke hospitalization rates, in addition they have explored these differences among a population as diverse as Florida. They also present new information about the racial/ethnic differences in ischemic and hemorrhagic stroke separately, as well as examining racial differences in stroke rates over time (2000-2006). Since the 1990s, numerous articles and editorials have called for a reduction in the racial/ethnic differences in stroke rates. Pathak and Sloan [2] demonstrate that, at least in Florida, there have been no reductions in these race/ethnic differences from 2000 through 2006. Future studies examining why the rate of stroke is high among blacks are desperately needed, particularly for younger adults in which disparities are greatest.

\section{References}

$\checkmark 1$ Chong JY, Sacco RL: Epidemiology of stroke in young adults: race/ethnic differences. J Thromb Thrombolysis 2005;20:77-83.

2 Barnett Pathak E, Sloan MA: Recent racial/ethnic disparities in stroke hospitalizations and outcomes for young adults in Florida, 2001-2006. Neuroepidemiology 2009;32:302-311.

-3 Centers for Disease Control and Prevention: Age-specific excess deaths associated with stroke among racial/ethnic minority populations United States, 1997. MMWR Morb Mortal Wkly Rep 2000;49:94-97.

-4 Ayala C, Croft JB, Greenlund KJ, Keenan NL, Donehoo RS, Malarcher AM, Mensah GA: Sex differences in US mortality rates for stroke and stroke subtypes by race/ethnicity and age, 1995-1998. Stroke 2002;33: 1197-1201.

5 Jacobs BS, Boden-Albala B, Lin IF, Sacco RL: Stroke in the young in the northern Manhattan stroke study. Stroke 2002;33:2789-2793.

-6 Kissela B, Schneider A, Kleindorfer D, Khoury J, Miller R, Alwell K, Woo D, Szaflarski J, Gebel J, Moomaw C, Pancioli A, Jauch E, Shukla $\mathrm{R}$, Broderick J: Stroke in a biracial population: the excess burden of stroke among blacks. Stroke 2004;35:426-431.

7 Kittner SJ, McCarter RJ, Sherwin RW, Sloan MA, Stern BJ, Johnson CJ, Buchholz D, Seipp MJ, Price TR: Black-white differences in stroke risk among young adults. Stroke 1993;24(suppl 12):I13-I15, discussion I20I21.

8 Stewart JA, Dundas R, Howard RS, Rudd AG, Wolfe CD: Ethnic differences in incidence of stroke: prospective study with stroke register. BMJ 1999;318:967-971.

-9 Rosman KD: The epidemiology of stroke in an urban black population. Stroke 1986;17:667-669.

10 Radhakrishnan K, Ashok PP, Sridharan R, Mousa ME: Stroke in the young: incidence and pattern in Benghazi, Libya. Acta Neurol Scand 1986;73:434-438.

-11 Smadja D, Cabre P, May F, Fanon JL, Rene-Corail P, Riocreux C, Charpentier JC, Fournerie P, Saint-Vil M, Ketterle J: Ermancia: epidemiology of stroke in Martinique, French West Indies. I. Methodology, incidence, and 30-day case fatality rate. Stroke 2001;32:2741-2747.

\section{Norrina Allen}

Pre-Doctoral Fellow, Department of Chronic Disease Epidemiology Yale School of Public Health, Center for Outcomes Research

1 Church St, Suite 200, New Haven, CT 06510 (USA)

Tel. +1 203764 5672, Fax +1 2037645892

E-Mail Norrina.allen@yale.edu

\section{KARGER}

Fax +41 613061234 E-Mail karger@karger.ch www.karger.com
C 2009 S. Karger AG, Base

0251-5350/09/0324-0312\$26.00/0 